\title{
Comunicación

\section{Agentes del sector cinematográfico y la diversidad cultural en Colombia}

Si bien las actuales políticas cinematográficas que fomentan la diversidad cultural han incrementado la producción de largometrajes nacionales y el interés por los mismos, la experiencia del cine es aún reservada para unos pocos sectores. Es en la interacción de las lógicas e intereses de los agentes del sector donde se pueden identificar los desafíos que la diversidad cultural enfrenta en Colombia.

PALABRAS CLAVES: cine colombiano, políticas de cine, industrias culturales, modelo de fomento cinematográfico, políticas de cine en Colombia.
Existing policies in film-making inspired in the notion of cultural diversity have increased the production of indigenous films in Colombia while boosting attendance to movie theatres. Participation in the cinema experience is however still reserved for certain privileged social groups. This article looks at the rationale of film producers and their interests as sites for the identification of challenges cultural diversity faces in Colombia.

KEY WORDS: Colombian cinema, film policies, cultural industries, film promotion, film policies in Colombia.

Asistente sociocultural, University of British Columbia, Canadá.

Correo electrónico: liliana.castaneda@ubc.ca 
Este ensayo se propone hacer un análisis descriptivo del sector cinematográfico que identifique a los principales actores del mercado en Colombia, sus lógicas, intereses y poder de negociación. Al exponer estos elementos se podrán discutir los desafíos a la diversidad cultural tan relevantes en este país como en cualquier otro de Latinoamérica, debido a las condiciones del mercado del cine donde históricos cuellos de botella marcan las diversas etapas de la cadena productiva y la posición de desventaja de la producción nacional con respecto de la preponderancia en número y asistencia a las películas de Hollywood conlleva a la exclusión en cuanto al acceso y a la invisibilidad de las historias propias en la oferta audiovisual.

Por lo tanto, la diversidad cultural se entiende no sólo como la producción de contenidos audiovisuales -en este caso largometrajes de ficción- que difundan el capital cultural colombiano, sino desde quiénes los realizan, qué se representa, a quiénes se les da acceso y quiénes los consumen. De nada sirve que estos bienes se realicen si se quedan olvidados en las oficinas de los productores y la población no participa de tal experiencia. En este sentido, el concepto se suscribe a los principios de la Convención para la Protección y Promoción de la Diversidad de Expresiones Culturales de la Organización de las Naciones Unidas para la Educación la Ciencia y la Cultura (UNESCO, 2005, p. 5) respecto de la diversidad cultural como "los distintos modos de creación artística, producción, difusión, distribución y disfrute de las expresiones culturales" (UNESCO, 2005, art. 4). De ahí que los actores estudiados se sitúen en las distintas etapas de la cadena de valor para así conocer los imperativos que condicionan la diversidad cultural a través de todo el proceso: producción, distribución y exhibición.

Esta premisa conduce a que el análisis de las políticas culturales adopte un sentido holístico (Thompson, 1997, p. 2) que no sólo incluya la acción del Estado sino que tenga en cuenta otros agentes que interactúan en el sector del cine con sus intereses, muchas veces contradictorios, en una dinámica de constante conflicto y negociación. De igual manera, el tema de los actores sectoriales se analiza desde una perspectiva histórica porque si bien el contexto bajo estudio se ubica entre 1997 y 2009, hay continuas referencias al modelo anterior (19721993) también denominado la era de FOCINE (Compañía de Fomento Cinematográfico) y a la etapa neoliberal (1993-1997). 
Por último, los desafíos a la diversidad cultural se analizan principalmente desde la dimensión económica, de ahí que se tomen en cuenta indicadores de mercado como el número de estrenos audiovisuales nacionales y extranjeros, el número de pantallas, el tamaño de la taquilla y la audiencia, la participación de distribuidores y exhibidores en el mercado, las percepciones, el acceso y prácticas de los consumidores, y no sólo se consideren las narrativas de las películas desde la perspectiva de incluir o no historias de sectores marginados y desde las percepciones del público y los críticos. ${ }^{2}$

En la primera parte se expondrán las políticas cinematográficas en cuanto al discurso y estructura oficial como eje central del sector donde la función social del cine compite con el fomento de la industria. Posteriormente se presentarán a los demás agentes como realizadores (productores y directores), críticos, distribuidores, exhibidores y audiencias al tiempo que se discuten los conflictos que la aplicación de los instrumentos de fomento como subsidios y cuotas de pantalla, entre otros, representa para sus intereses y para la consecución de la diversidad cultural.

\section{EL ESTADO}

El Estado se ubica en el epicentro del modelo de desarrollo cinematográfico al ser el principal promotor y regulador del sector. Al analizar el discurso oficial en general, se encuentran justificaciones de distinta naturaleza: en primer lugar, están los beneficios sociales de los largometrajes como bienes públicos. Estos beneficios o externalidades son redistribuidos en la sociedad a través de políticas oficiales que de otra manera no podrían realizarse o sobrevivir como Cwi (1982, p. 59) lo ha indicado respecto del apoyo oficial a las artes. Por ejemplo, los bienes culturales diseminan significados sociales debido al potencial simbólico de representar la identidad nacional y el contexto donde esas identidades interactúan. La recreación de situaciones, sentimientos y conflic-

2 La metodología de este trabajo incluyó una revisión bibliográfica de libros e informes oficiales y de otros investigadores; además se realizaron entrevistas a diversos representantes del sector y una encuesta sobre hábitos de consumo de cine con una muestra aleatoria de 10 familias colombianas. 
tos, entre otros, motivan al público a crear sentido de lo que se ve en su contexto social. De esta manera, como sostienen Hoskins, McFadyen y Finn (1997, p. 82) las películas de ficción tienen la capacidad de cultivar el sentido de pertenencia y ciudadanía.

Otra razón de peso tiene que ver con la naturaleza económica de las películas: la producción de estos bienes implica altos costos fijos y una taquilla incierta (Grant \& Wood, 2004, p. 67). En ausencia de economías de escala y debido a la dificultad de predecir el éxito que tenga o no la película en la taquilla, realizadores de cine en países en vías de desarrollo se ven en la necesidad de solicitar ayuda oficial para sobrellevar los costos y riesgos de producción. De manera general, el Estado le inyecta al sector el empujón inicial para que despegue y, a largo plazo, se sostenga.

Las fallas del mercado del cine en estos países constituyen el tercer argumento que justifica el modelo de fomento cinematográfico. El predominante número de películas de Hollywood presentes en el mercado colombiano, 102 en 2008 (véase Figura 1), es el resultado directo de la acción oligopólica de los majors que controlan cerca de $80 \%$ del mercado. En este caso, las políticas oficiales tendrían que asegurar la diversidad de contenidos, condiciones equitativas de participación y la asignación eficiente de recursos. Estos objetivos se relacionan con una justificación de carácter moral que ha asumido el Estado al intervenir en el mercado en nombre de la "eficiencia y equidad" (Picard, 1989, p. 95 ) en la provisión de bienes públicos a actuales y futuras generaciones.

\section{FIGURA 1}

NÚMERO DE ESTRENOS POR ORIGEN

EN EL MERCADO COLOMBIANO (2008)

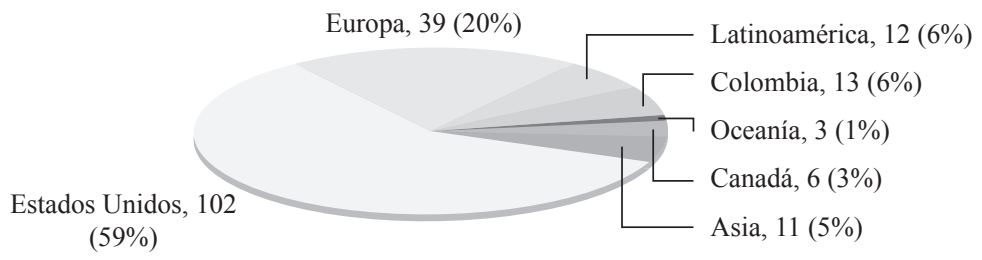

Fuente: J. M. Mutis, comunicación personal, 19 de diciembre, 2009. 
Históricamente estos argumentos culturales y económicos han justificado las políticas de cine en Colombia, sin embargo su aplicación en términos de las responsabilidades oficiales e implementación ha cambiado en cada época. En el primer intento de fomento industrial centralizado, que comienza con la Ley de Sobreprecio (1972) y la creación de FOCINE (1978), el Estado terminó asumiendo la financiación, distribución y exhibición de películas con pérdidas que se calculan en 1,757 millones de pesos o 3'066,081.42 dólares de hoy ${ }^{3}$ hasta la eventual parálisis de la institución 10 años después y su formal liquidación en 1993 (Historia de un fracaso, 1 de marzo, 1993). Aunque en esta época se le dio un impulso definitivo a la memoria audiovisual con 31 largometrajes, 140 mediometrajes y la formación de los cuadros técnicos y artísticos, no se logró construir un discurso nacional incluyente o exitoso ni se sentaron las bases de una industria sostenible. La producción audiovisual de corte rural y filiación literaria de poco interés para el público masivo y los escándalos de corrupción y clientelismo que azotaron a FOCINE cimentaron la oposición hacia cualquier futuro apoyo al sector.

Durante la subsecuente etapa neoliberal (1988-1997), el Estado ignoró por completo la función social del cine y proclamó la eficiencia del mercado al reducir sustancialmente los subsidios, eliminar los incentivos, suprimir el control oficial sobre el precio del boleto de cine y autorizar la diseminación de las salas multiplex sin haber establecido condiciones industriales de competitividad para los largometrajes nacionales. Aunque la producción se redujo a menos de 10 títulos durante los años noventa, se estrenaron hitos dentro de la memoria audiovisual del país por su innovación en la estética y en su aproximación a la realidad colombiana como “Confesión a Laura" (1990), "Rodrigo D: no futuro" (1991), "La gente de La Universal" (1991) y "La estrategia del caracol" (1993).

En la actual etapa posneoliberal, el restablecimiento de las políticas cinematográficas fue posible debido a una combinación de elementos positivos como las iniciativas previas en Brasil, Argentina y México; un contexto interno favorable donde se buscó consenso y compensación

3 Basado en la evolución del índice de precios al consumidor en Estados Unidos y Colombia en 1993 y hasta junio de 2010 y la tasa de cambio de la época (\$863.06); esta cifra equivaldría a 8,609’547,116 pesos a junio de 2010. 
entre las partes involucradas; el surgimiento de nuevas generaciones educadas visualmente, y un grupo de presión interna de directores de cine, investigadores e intelectuales que logró ocupar puestos de poder para impulsar y estructurar el modelo de apoyo. ${ }^{4}$ En el nuevo discurso oficial, se entremezclan justificaciones de índole tecnocrática que enfatizan en la contribución económica del cine (Convenio Andrés Be1lo, 2003) y la reducción del Estado y el valor cultural al declarar los productos audiovisuales como bienes de interés social (Congreso de Colombia, 2003), lo que reafirma el doble objetivo de fomento industrial y protección a la diversidad cultural consignados en la Ley General de Cultura de 1997.

\section{ESTRUCTURA DEL MODELO}

Aunque en el nuevo modelo se ha intentado descentralizar la toma de decisiones y disposición de recursos - de ahí se deriva la creación de los Consejos Departamentales y Municipales de Cinematografía-, aún es evidente la concentración de poder desde la capital Bogotá donde se ubican el Ministerio de Cultura, como principal ente regulador; la Dirección de Cine, dependiente del Ministerio y encargada de diseñar e implementar las políticas de producción, formación, investigación e información, patrimonio y circulación de contenidos audiovisuales, y Proimágenes en Movimiento, recolector de la cuota parafiscal, 5 administrador del Fondo de Desarrollo Cinematográfico (FDC) y encargado de la Comisión Fílmica. A esto se le suma el hecho de que la mayoría de centros educativos, personal técnico, artistas, inversionistas y compañías productoras también se ubican en Bogotá. Es decir, a pesar de que la ley se inspira en los principios de diversidad al darles voz y voto a los

4 Por ejemplo, el director de cine Felipe Aljure lideró la Dirección de Cinematografía en su primera etapa y el economista e investigador David Melo fue el segundo director; Claudia Triana, con más de 25 años de experiencia en el sector, asumió la dirección de Proimágenes en Movimiento.

5 Los productores aportan 5\% de sus ganancias; los distribuidores $8.5 \%$ de la taquilla neta, y los exhibidores $8.5 \%$ de los rendimientos por comercializar películas foráneas para nutrir el Fondo de Desarrollo Cinematográfico (FDC). 
municipios y departamentos dentro del Consejo Nacional de las Artes y la Cultura en Cinematografía (CNACC) su poder sigue siendo limitado por la misma dinámica del sistema industrial.

Esta estructura (véase Figura 2) es mucho más compleja que la del primer modelo de los años ochenta, no sólo por el número de instituciones implicadas, como el Ministerio de Hacienda y la Dirección de Aduanas (DIAN), entre otras, sino por la combinación de lógicas privadas y públicas con fines comerciales y artísticos que inspiran las políticas cinematográficas, lo que confirma la tendencia paradójica de reregulación observada después de la implementación de políticas neoliberales de segunda generación que supuestamente deberían propender por la reducción del Estado (Hall, 1997, pp. 228-230).

La naturaleza de los estímulos en forma de subsidios también refleja la complejidad de los objetivos que las autoridades cinematográficas quieren impulsar y los desafíos de materializar la diversidad cultural entendida desde la participación y acceso universal a los contenidos. Por un lado está la Dirección de Cine con el Plan de Política Audiovisual Nacional (PAN) que aspira a construir la cultura audiovisual al "fomentar experiencias cinematográficas y audiovisuales, complementarias al desarrollo profesional e industrial del cine" (Ministerio de Cultura, 2010) a cargo de individuos o colectivos con un interés educativo y cultural y dirigidas a comunidades olvidadas o vulneradas. Los programas del Plan cubren la formación en realización y apreciación, investigación y publicaciones, patrimonio audiovisual, premios nacionales de cine y documentales con temáticas determinadas -en 2009, por ejemplo, el foco fue el Bicentenario de la Independencia y Lenguas nativas- y han alcanzado los 7,325 millones de pesos (\$3'649,089.59 de dólares) entre 2007 y 2009 (Ministerio de Cultura, 2010).

Sin embargo el alcance de estos incentivos es muy restringido. Por ejemplo, aunque los estímulos en el campo de la formación en 2008 y 2009 se otorgaron a proyectos que incluyeron a jóvenes de comunas - 0 barrios populares-, indígenas del Sinú, comunidades pequeñas en Los Montes de María, etc., muchos de los productos finales como videos o cortometrajes han tenido una exhibición limitada, desperdiciando la oportunidad de dar a conocer su perspectiva de representación a otras audiencias. De acuerdo a Jorge Mutis (comunicación personal, 19 de 


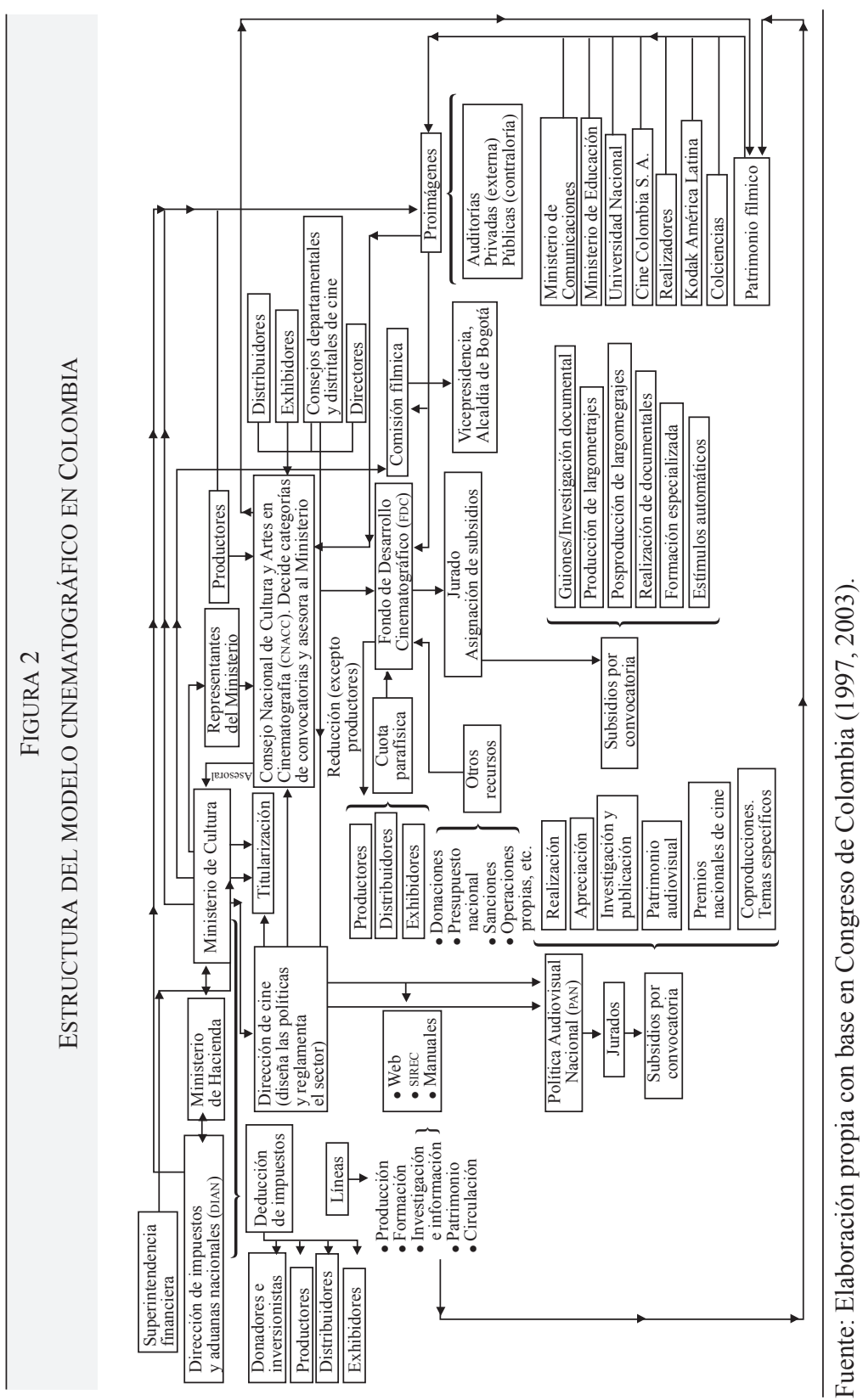


diciembre, 2009), coordinador del grupo de políticas e investigación, la presentación de los resultados de estas iniciativas se realiza en círculos cerrados sin salida comercial porque éste no es el propósito.

Otro programa interesante en la modalidad de apreciación es la "Maleta de películas" que es un catálogo de 118 títulos locales y extranjeros entregado desde 2000 a instituciones educativas y culturales para ser presentados a sus usuarios y fomentar la apreciación crítica audiovisual. No obstante, una evaluación preliminar en 2006 mostró que algunas de estas entidades nunca cumplieron su objetivo de acuerdo a Frank Patiño (2006), oficial de comunicaciones de la División de Cine. Esto condujo a la revisión del programa y el acompañamiento con una herramienta pedagógica para aprovechar la utilización de los títulos de la "Maleta...".

Por otro lado, están los subsidios del FDC que apoyan aquellos proyectos de índole comercial para que puedan ser estrenados en el circuito nacional y cobijan principalmente las etapas de producción y posproducción y en menor medida escritura de guiones, realización de cortos y documentales y formación especializada. También existen los estímulos automáticos para la promoción del estreno de la película en territorio nacional y la participación internacional.

Dado que los subsidios del FDC provienen de una cuota parafiscal recolectada de los productores, distribuidores y exhibidores, el Estado no asume la función de productor $\mathrm{y}$, por ende, no corre el riesgo de caer en déficits fiscales como sucedió en la etapa de FOCINE. En promedio, se han entregado 33,855'078,964 pesos (13'234,462.67 dólares) entre 2004 y 2009 (Proimágenes en Movimiento, 2009b). Aunque el éxito inicial del modelo se debió en parte a que muchos proyectos ya habían arrancado y sólo necesitaban el empujón final en la etapa de posproducción, los mecanismos de política cinematográfica han generado mayor financiación y número de estrenos, pasando de un promedio anual de 2 películas durante los años noventa a un promedio de 7.6 en la presente década (véase Figura 3). Esto en teoría impulsaría la diversidad de contenidos, pero como se verá en la sección de los críticos, las temáticas aún siguen siendo excluyentes.

Aparte del mayor espectro que cubren los proyectos apoyados por el FDC frente a los del PAN, otro cuestionamiento sale a relucir con 
FIGURA 3

PRODUCCIÓN NACIONAL 1994-2009

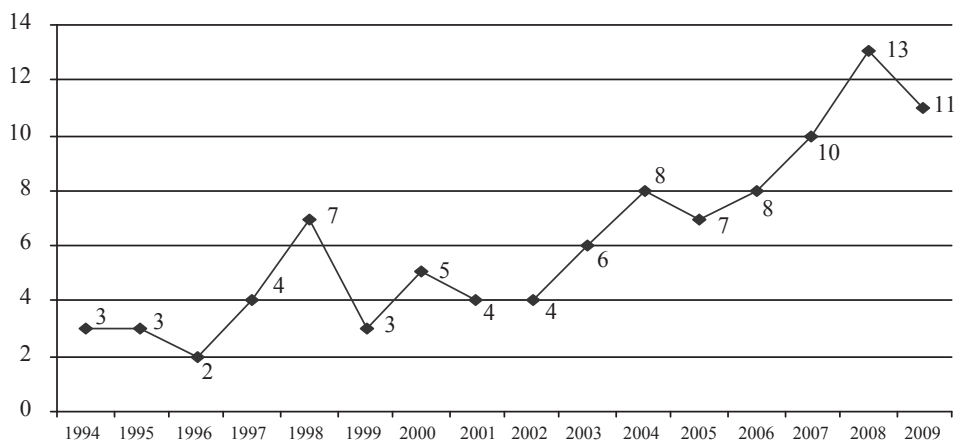

Fuente: Proimágenes en Movimiento (2009a).

respecto de la supuesta prioridad de difundir la diversidad cultural y la financiación de los programas oficiales. Mientras el FDC es autosuficiente, los fondos de los programas culturales del PAN provienen del presupuesto nacional lo que cuestiona la sostenibilidad de dichas políticas en caso de recortes del gasto fiscal o una crisis económica. Es decir, los programas que encarnan el objetivo central de la diversidad cultural se dejan a merced de la agenda política del gobierno y del estado de la economía, de por sí bastante inestable.

\section{LOS REALIZADORES}

A pesar de que las políticas de fomento han favorecido la aparición de compañías productoras y fortalecido a aquellas pocas de más larga trayectoria, el poder de negociación de las mismas es muy bajo debido a la acción de otros agentes, como se verá más adelante, y a las condiciones del sector. En la actualidad se observa un alto número de pequeñas firmas que compiten en el mercado con baja intensidad de capital, desde economías de escala y altas barreras de entrada debido a los altos costos de los largometrajes y la incertidumbre sobre la recuperación de la inversión. Por lo tanto, la mayoría de las empresas combina la producción de 
películas de ficción con otros productos audiovisuales como programas de televisión y comerciales para asegurar la recuperación en caso de que el proyecto fílmico fracase y debido a que el trabajo en el sector es inestable. Las estrategias tradicionales de producción como el canje laboral, convergencia de funciones y financiación familiar, coexisten con la especialización de acciones propias del cine de productor en oposición a la prevalencia del cine de autor durante la época de FOCINE.

Estas tendencias generales han permitido que actualmente las compañías más fuertes alcancen inversiones de más de 10 millones de dólares por largometraje cuando en los años ochenta el promedio era de 1 millón de dólares, y que hayan podido realizar tres o cuatro proyectos en promedio en la presente década como es el caso de Dago García Producciones, CMO Producciones o Dynamo, en comparación con la corta vida que tenían las productoras del pasado (Martínez Pardo, 1978). De esta manera se ha roto el viejo mito de sólo poder terminar una película antes de declararse en bancarrota o de esperar un promedio de 10 años para comenzar el siguiente largometraje.

Los debates en el campo de la producción con respecto de la diversidad cultural tienen que ver con la inclusión o no de un amplio espectro de sectores de la población en la construcción de la memoria audiovisual nacional y con los temas de los proyectos desarrollados por estas casas productoras y realizadores. En primer lugar, es importante observar quiénes están produciendo los contenidos audiovisuales, como un reflejo más de la diversidad o no presente en el sector. Adriana Bernal, una reconocida directora de fotografía, declara que "A excepción de la actuación, tradicionalmente el sector del cine ha sido controlado por hombres, desde la producción hasta la parte técnica y, por ejemplo, hasta ahora se ven luminotécnicas mujeres" (Comunicación personal, 5 de diciembre, 2007). Y aunque la diversificación de los realizadores sigue siendo limitada, no se puede comparar la participación histórica del sector femenino, que comenzó a abrirse paso desde la época de FOCINE y hoy tiene más exponentes en la dirección y producción, con otros grupos marginados como los indígenas, las negritudes y la población lesbiana, gay, bisexual y transexual (LGBT), cuya participación en la creación de largometrajes sigue siendo inexistente. Esto se reafirma si se tiene en cuenta que incluso el término general "mujeres" en este 
contexto desconoce que aquellas que han incursionado en el mundo del cine pertenecen a una clase media o media alta, han tenido estudios en el exterior y no forman parte de las minorías anteriormente nombradas.

El segundo punto en cuestión son los parámetros para escoger los temas y perspectivas de acercamiento que comúnmente deciden ser apoyados para largometrajes de ficción. Si bien esto depende de cada productor, la reproducción del capital cultural no es necesariamente una prioridad para todos cuando hay imperativos comerciales para asegurar la financiación y la sostenibilidad. El productor Rodrigo Guerrero afirma:

Uno no va a cine a que le echen un discurso político, no es un discurso de cambio social, no es un panfleto sociopolítico a través del cual estamos haciendo denuncias de la sociedad o de la violencia en Colombia. Yo creo que aquí nos lo estamos viendo como una cuestión de entretenimiento Guerrero (Uno no va a cine, 2007, p. 28).

Esto representa una paradoja para el modelo de fomento ya que si bien la legislación establece claramente la diversidad cultural como el principal objetivo de la política cultural, no se puede coartar la libertad creativa en aras de aquellos temas o estéticas que cumplan con los requerimientos oficiales. ¿Se cumple entonces el fin cultural con el solo hecho de producir largometrajes nacionales sin importar los contenidos que estos títulos muestren?

Para otros directores y productores el fin del cine sí constituye imprimir una mirada de reflexión sobre la cotidianeidad. "Toca cuestiones que son afines a cualquier ser humano, pero lo hace desde nosotros, desde nuestra experiencia, nuestra cultura, nuestra riqueza, pocas veces explotada en la cinematografía", afirma el director Ciro Guerra respecto a su largometraje "Los viajes del viento" (Los viajes del viento, 23 de abril, 2009). Sin embargo y a pesar de los premios que obtuvo esta película en festivales internacionales, la taquilla interna fue de apenas 162,126 espectadores.

\section{CRÍTICOS}

Al indagar sobre el aspecto de la diversidad relacionado con las narrativas y estéticas de los largometrajes, se observa que éste es uno de los 
mayores puntos de conflicto entre críticos, productores y audiencia, e inclusive dentro de estos mismos grupos.

TABLA 1

LARGOMETRAJES DE FICCIÓN DE MAYOR AUDIENCIA

(MÁS DE 1 MILLÓN)

\begin{tabular}{|c|c|c|c|}
\hline Película & Director & Género & Audiencia \\
\hline $\begin{array}{l}\text { "Esposos en } \\
\text { vacaciones" (1978) }\end{array}$ & Gustavo Nieto Roa & Comedia & $1 ' 250,000$ \\
\hline $\begin{array}{l}\text { "El taxista } \\
\text { millonario" (1979) }\end{array}$ & Gustavo Nieto Roa & Comedia & $1^{\prime} 500,000$ \\
\hline $\begin{array}{l}\text { "El inmigrante } \\
\text { latino" (1980) }\end{array}$ & Gustavo Nieto Roa & Comedia & $1 ’ 300,000$ \\
\hline $\begin{array}{l}\text { “Tiempo para } \\
\text { amar" (1980) }\end{array}$ & $\begin{array}{l}\text { Manuel José } \\
\text { Álvarez/ prod. } \\
\text { Gustavo Nieto R. }\end{array}$ & Drama & $1 ' 100,000$ \\
\hline $\begin{array}{l}\text { "Padre por } \\
\text { accidente" (1982) }\end{array}$ & Manuel Busquets & Comedia & $1^{\prime} 012,000$ \\
\hline $\begin{array}{l}\text { "El niño y el papa" } \\
\text { (1987) }\end{array}$ & Rodrigo Castaño & Aventura/drama & $1 ' 100,000$ \\
\hline $\begin{array}{l}\text { "La estrategia del } \\
\text { caracol" (1994) }\end{array}$ & Sergio Cabrera & Comedia/drama & $1 ' 500,000$ \\
\hline $\begin{array}{l}\text { "Rosario Tijeras" } \\
(2005)\end{array}$ & Emilio Maillé & Drama & $1^{\prime} 053,030$ \\
\hline $\begin{array}{l}\text { "Soñar no cuesta } \\
\text { nada" (2006) }\end{array}$ & Rodrigo Triana & Drama & $1 ' 198,172$ \\
\hline
\end{tabular}

Fuentes: Taquilla en rojo (1983), Eskpe (2005), Proimágenes en Movimiento (2009a).

Como se puede observar en la Tabla 1, la comedia es el género que ha asegurado el mayor número de espectadores a lo largo de la historia, sin embargo este éxito no ha escapado de críticas que la consideran un "género menor". Las comedias de mayor éxito como "El taxista millonario" y "El inmigrante latino" de Nieto Roa han sido calificadas como ejemplos de "mal gusto" y "productos estandarizados" por críticos de 
renombre como Mauricio Laurens (Palacios Obregón, 2004). Paradójicamente, este desprecio choca con los objetivos de sostenibilidad y continuidad de las políticas de fomento porque son precisamente los productores que le han apostado a la comedia aquellos que han asegurado la financiación para proyectos posteriores.

Más allá del género, las narrativas actuales representan otra fuente importante de conflicto entre los principios de apoyo oficial y lo que se ve en la pantalla. Los críticos de cine han señalado el énfasis de los largos respecto de la recreación de temas de la clase media, urbana, popular, masculina y tradicionalista que no sólo ha excluido propuestas innovadoras en cuanto a la estética y a los guiones, sino a grupos sociales que no se sienten representados debido a su género, religión, clase social, cultura u orientación sexual. Pedro Antonio Zuluaga, crítico e investigador explica:

Las películas de ficción hechas en Colombia se han centrado históricamente en meta-relatos: la violencia, la pobreza, las drogas mientras que otros formatos como los documentales y los cortometrajes han canalizado otros sectores que aún luchan por ser reconocidos y por producir sus contenidos (Comunicación personal, 21 de octubre, 2006).

La transición hacia narrativas más diversas y más íntimas ha sido un proceso lento en Colombia. De hecho, el Ciclo Rosa, que es un festival de muestra especializado en temática LGBT apenas comenzó en 2001, en medio de una gran controversia y con una participación marginal de realizadores colombianos. "El Ciclo Rosa proyecta principalmente material internacional y sólo algunos cortometrajes locales de aquellos grupos que responden a la convocatoria. Hemos presentado cerca de un promedio de tres cortos nacionales por festival", afirma Catalina Rodríguez, antigua directora de Audiovisuales del Instituto Distrital de Cultura y Turismo de Bogotá (Comunicación personal, 21 de noviembre, 2006).

La otra crítica frecuente respecto de los títulos nacionales es el uso de "fórmulas de televisión o hollywoodenses" para atraer audiencia. Por ejemplo, "Rosario Tijeras" (2005) fue criticada por exponer excesiva violencia y desnudez mientras "Soñar no cuesta nada" (2006) fue considerada un ejemplo del melodrama telenovelero en la pantalla grande con un 
relato anecdótico, actores famosos, efectos visuales y una banda sonora comercial. La aproximación pesimista hacia los largometrajes exitosos como vulgarización o comercialización del arte por parte de los críticos evoca el llamado nostálgico que hizo en su tiempo la Escuela de Frankfurt hacia el regreso a la "alta cultura" como concepto positivo y opuesto a la cultura de masas, pasando por alto las complejidades que toman lugar dentro de las industrias culturales (Hesmondhalgh 2007, p. 16), ya que no hay que olvidar que, como sostiene Suárez (2007), en estas comedias y melodramas "también hay retazos de nación" (p. 85).

Los realizadores, por su parte, defienden la existencia de distintas corrientes dentro de la cinematografía ofrecida en el mercado. Alberto Amaya, director de la Escuela de Cine y Televisión de la Universidad Nacional, comenta:

Cada tipo de cine, el comercial y el de contenido social, tiene sus objetivos claros. Dago (García) ha abierto un camino que demuestra que con bajos recursos, socios y personal técnico del medio (televisivo) hay logros económicos. Y esto es un incentivo para la industria. En un país pobre lo cultural y lo social puede ser financiado por el Estado, pero lo positivo es que también se dé desde la industria. Hay otros casos como "La gente de la Universal" que es un modelo donde el director desarrolla esa línea de tocar la sensibilidad social con rentabilidad (Comunicación personal, 3 de noviembre, 2006).

\section{DISTRIBUIDORES}

Como en otros países de Latinoamérica, los grandes estudios de Hollywood o majors tienen un alto poder de negociación al tener una oferta constante y amplia de películas de gran aceptación por parte del público en general. Esto ha tenido dos importantes consecuencias. La primera es el papel crucial que estos actores cumplen dentro del modelo, ya que al ser penalizados por distribuir películas extranjeras, se convierten en últimas en los principales contribuidores del FDC.

La segunda consecuencia es la alta concentración del mercado de la distribución en Colombia por parte de los majors, valiéndose de distintas estrategias. Por ejemplo, Columbia Tristar que controla 37\% del mercado y United International Pictures con 15\%, cuentan con ofici- 
nas propias en Bogotá, mientras Elephant-Time-Warner (28\%) tiene un acuerdo con una empresa local, Cine Colombia, para distribuir sus películas (López, 2004, p.15). De esta manera, el resto 20\% se reparte entre un grupo numeroso de pequeñas compañías nacionales. Federico Mejía, director de la distribuidora Babillá Cine, afirma:

Aunque el mercado es prácticamente manejado por unas cuantas corporaciones, aún hay espacio para que otros participen de un negocio que reporta ganancias anuales de 330,000 dólares. Nosotros nos dirigimos al circuito independiente que es aproximadamente $10 \%$ de la audiencia total en el país, y esto es un incentivo para seguir trabajando (Comunicación personal, $15 \mathrm{de}$ febrero, 2007).

Pero si bien la distribución de largometrajes de Hollywood es boyante, otro panorama muy distinto sucede con los títulos colombianos, lo que deriva en una histórica invisibilidad de la propia representación en territorio nacional. De acuerdo a entrevistas con productores colombianos, la distribución de películas nacionales no sigue el mismo proceso de los largometrajes extranjeros donde las casas de distribución negocian los derechos con los productores y después establecen acuerdos con los exhibidores. En este país, los productores negocian directamente con los exhibidores o con empresas que cumplen la doble función de distribuidor y exhibidor como Cine Colombia, generando que estos agentes tengan la última palabra al aprobar -o no- la proyección de las películas nacionales en sus salas. Es decir, para lograr llevar un largometraje a las pantallas se debe cumplir con los parámetros técnicos, artísticos y comerciales que habiliten su proyección. Al indagar si dichos parámetros incluían el fomento de la diversidad cultural colombiana, Carlos Llano, gerente de distribución de Cine Colombia, declaró que "la intención de Cine Colombia es apoyar el cine nacional" (Comunicación personal, diciembre, 2006), pero en otra entrevista aclara que la inversión y el apoyo de esta empresa es selectiva porque "no todas las películas tiene el mismo nivel comercial" (El público nacional está de romance, 2007, p. 60).

En el plano internacional la difusión del capital cultural se cumple mayoritariamente en los festivales de cine como parte de la estrategia 
de internacionalización de la Dirección de Cine e iniciativas individuales de distribución. De obtener el apoyo para participación internacional, los largometrajes tienen oportunidad de exhibirse y eventualmente firmar un contrato de distribución como en el caso de "Perro come perro" de Carlos Moreno (2008) y "Celluloid dreams" durante el Festival Sundance. Otra posibilidad es pre-establecer un contrato de participación en las ganancias como sucedió con "María llena eres de gracia" de Joshua Marston (2004) distribuida por HBO o "Satanás" de Andy Baiz (2007) por parte de Cine Colombia. Otros productores simplemente han firmado contratos con firmas internacionales como CMO Producciones y la empresa española Latido Films. Sin embargo, el acceso mundial a los títulos es aún muy restringido e incluso no es común encontrar películas colombianas para descargar o ver en sitios en línea después de que fracasara el proyecto oficial de ofrecerlas en Jump TV en 2006. Esto significa que la disponibilidad de contenidos audiovisuales se remite básicamente al circuito comercial interno de por sí bastante limitado, excluyendo otros públicos globales, como los diaspóricos.

\section{EXHIBIDORES}

Históricamente estos actores han contado con un alto poder de negociación e incluso combatieron los impuestos aplicados al boleto de cine durante la época de FOCINE, llegando a protagonizar una larga batalla legal contra el gobierno que concluyó con la recolección parcial de las contribuciones a cambio de amnistías fiscales en 1988.

En el presente, estos agentes siguen ejerciendo un amplio control sobre el mercado con tan sólo cuatro compañías manejando 69\% del total: Cine Colombia con 40\%; Procinal, 13\%; Cinemark, 7\% y Royal Films, 9\%, lo que conduce a una situación de oligopolio en la demanda (López, 2004, p. 16). Las demás empresas son pequeñas y de tipo familiar, pero aún está por verse cómo la entrada de la multinacional mexicana de salas de cine Cinépolis en 2008 reconfigurará las fuerzas del mercado.

De todas las compañías de exhibición Cine Colombia, adquirida por la sociedad financiera Valorem en 2009 que también controla el canal de televisión Caracol, representa un caso especial no sólo porque capta 
$64 \%$ de la taquilla nacional, sino porque posee la red de pantallas de cine más grande, con 204 en total. De esta manera Cine Colombia ejerce un alto poder de negociación frente a los productores para quienes firmar un contrato con esta empresa significa tener acceso a más pantallas. Esto es clave en el negocio si se considera que el theatrical o salas de cine es la ventana de exhibición que en la mayoría de los casos -si no en su totalidad- permite la recuperación de la inversión. ${ }^{6}$ Catalina Samper, productora de "El Colombian dream", argumenta que "no hay muchas opciones además de Cine Colombia. Cinemark (Colombia S.A.) hubiera podido ser, pero no tiene salas en Cali y en Colombia se hace la taquilla en Bogotá, Medellín y Cali” (Comunicación personal, 8 de noviembre, 2006).

Para combatir el control de estos actores sobre el mercado, el artículo 18 de la Ley de Cine declara que el gobierno establecerá anualmente una cuota de pantalla para proyectar títulos nacionales en consulta con otros agentes y de acuerdo a las condiciones del sector. Este instrumento no es nuevo en Colombia, pero sigue siendo uno de los más polémicos. El debate en términos generales se remite a establecer si la exhibición obligatoria de estas películas genera automáticamente audiencia más allá de su calidad artística o técnica. De un lado se ubican los productores y artistas nacionales que justifican la medida como una defensa contra los majors que monopolizan el mercado con las películas extranjeras. Del otro lado están los representantes de los negocios privados ya sean distribuidores y exhibidores nacionales o internacionales que proclaman el principio del libre mercado que debiera regir al sector.

Sin embargo, hasta la fecha la cuota no se ha reglamentado, es decir la norma no establece si la cuota se basa en un porcentaje del total de la oferta o de un número determinado de películas nacionales. Además no ha habido necesidad de aplicarla porque el número de estrenos locales es ínfimo comparado con los largometrajes de otros países. Por ejem-

6 En 2006 la Dirección de Cine empezó a comercializar un grupo de DVDs con El Círculo de lectores y en 2009 varios productores, incluyendo Dynamo Capital, también comenzó a vender 10 títulos a precios módicos, según Claudia Triana, directora de Proimágenes en Movimiento (Comunicación personal, 16 de septiembre, 2010). 
plo, en 2008 hubo 13 títulos nacionales frente a 193 extranjeros (véase Tabla 1). La pregunta entonces es qué pasará cuando la producción colombiana aumente a tal punto que represente un costo de oportunidad para los exhibidores. ¿Se recurrirá a la imposición de la cuota y la confrontación con ellos como en el pasado?

La ley tampoco establece medias de continuidad, es decir, un tiempo mínimo en cartelera, lo que sería de mayor utilidad porque si bien los largometrajes nacionales llegan a las salas de cine, lo que ocurre muchas veces es que se retiran de las pantallas si no cumplen los estándares de taquilla de los exhibidores. Esto representa otro desafío para las metas de diversidad cultural porque en últimas la decisión de proyectar y reproducir el capital cultural es dejada en manos de agentes privados con intereses económicos en juego. Esta afirmación no desconoce la dificultad de establecer tiempos mínimos de exhibición que se puedan considerar justos en un país donde en muchos casos no hay espectadores para las películas nacionales o donde la televisión es más popular que el cine.

Es por este último hecho que la cuota de pantalla en televisión puede ser más efectiva para la diversidad cultural, y al mismo tiempo, más polémica. Apenas en 2008 entró en rigor la cuota con el acuerdo 005 de la Comisión Nacional de Televisión (CNTV) para exhibir títulos colombianos equivalentes a mínimo $10 \%$ de la programación extranjera. Sin embargo, la Dirección de Cine comprobó en 2009 que no se cumplieron los términos del acuerdo y las películas extranjeras aún constituyen casi $100 \%$ del horario triple A en los canales privados. Una vez más se puede observar cómo la meta de difundir los valores culturales depende de los imperativos comerciales de los grupos más poderosos que manejan la televisión porque si bien se han pasado películas nacionales en los canales regionales, locales y públicos como Telecaribe, Citytv y Señal Colombia respectivamente, los canales privados no han hecho lo mismo y son los que precisamente captan la mayoría de la audiencia y, como si fuera poco, no se han tomado medidas para penalizarlos. Además, si se lee con detenimiento el acuerdo del CNTV, el horario de transmisión es muy amplio, entre las 6:00 de la mañana y 12:00 de la noche. Por lo tanto y parecido a lo que pasa con las películas en salas de cine, los canales pueden escoger un horario de baja audiencia para presentar las películas sólo por cumplir con el acuerdo y sin amenazar sus intereses. 
El segundo fenómeno recurrente en materia de exhibición es la concentración de las 593 pantallas existentes en las principales ciudades del país. Por ejemplo, Bogotá concentra $40.13 \%$ del total y se estima que sólo 4\% del total de 1,102 municipios cuenta con una sala de proyección (Proimágenes en Movimiento, 2009c). Dentro de las urbes, las salas se ubican mayoritariamente en barrios de clase media y alta, lo que limita el acceso al capital cultural audiovisual nacional. Si a esto se suma el precio del boleto que oscila entre 4 y 10 dólares y el corto ciclo de vida de las películas nacionales, la exclusión de aquellos sectores de la población que ganan el salario mínimo $(515,000$ pesos o 257 dólares mensuales) o menos es aún mayor.

En este sentido vale la pena mencionar que a pesar de estos obstáculos, la sociedad se las ingenia para ver las películas colombianas por vías legales como los festivales y muestras de cine, los cine-clubs, ${ }^{7}$ las salas de cine especializadas de la red Kaimán e ilegales como las copias piratas cuyo precio puede llegar hasta apenas 2 dólares. Aunque es difícil tener datos exactos del mercado negro, un estudio ha estimado en $38 \mathrm{mi}-$ llones de dólares las pérdidas para las industrias nacional e internacional de video (Convenio Andrés Bello, 2003, p. 9). También existen otras iniciativas con apoyo privado que dan cuenta de los puntos de encuentro entre los objetivos culturales y comerciales de los agentes: la Cine Gira. Este proyecto financiado por el canal privado Radio Cadena Nacional (RCN), Pastas Doria, Cinépolis y la Vicepresidencia comenzó en 2009 con el fin de llevar el cine a cerca de 320 municipios con pantallas inflables y entrada gratis. Si bien se puede cuestionar el hecho de que el proyecto estuvo al servicio del gobierno cuando se incluyó un mensaje presidencial como parte de la gira en 2010, de todas maneras no se puede negar que gracias a esta ventana de exhibición alternativa muchas personas han podido tener acceso al cine, incluso sentirlo por primera vez.

\section{AUDIENCIA}

Además de los desafíos en la producción, distribución, exhibición ya mencionados, muchos de ellos comunes en otros países de América

7 Actualmente organizados en la Red Nacional de Cine Clubs La iguana. 
Latina, ${ }^{8}$ Colombia presenta una especificidad que dificulta el éxito de las producciones locales: la percepción negativa en contra de las películas nacionales cuyo promedio de asistencia es de apenas 200,000 personas ("Taquilla en rojo", 1983; Proimágenes en Movimiento, 2009a).

La falta de entusiasmo por parte del público se deriva de la famosa ley de sobreprecio en 1972 que impulsó la excesiva producción de cortometrajes no siempre de la mejor calidad y que eran mostrados obligatoriamente antes de las películas en cartelera por parte de los exhibidores que querían obtener los incentivos oficiales (Álvarez, 2001). Este desánimo por lo nacional ha sido causa y consecuencia de otra tendencia también presente en otros países: la preferencia por otras cinematografías que han influenciado los hábitos del consumo de cine de los colombianos como la mexicana y argentina en décadas pasadas y la de Hollywood en décadas recientes. No obstante estos factores, las preferencias y actitudes de las audiencias han comenzado a modificarse. Una encuesta realizada en 2007 a una muestra aleatoria de 10 familias de Bogotá situadas en diferentes estratos socioeconómicos da cuenta de la combinación de la actitud pasiva tradicional y el actual interés que las nuevas producciones nacionales han generado.

En general, los encuestados han notado el incremento de la información sobre películas colombianas en medios de comunicación y boca a boca a pesar de no haber ido a verlas. De manera similar, los entrevistados no pudieron recordar los títulos exactos de los estrenos en los últimos cinco años, pero sí los temas generales, escenas de los trailers o actores participantes. Otra conclusión interesante es la percepción general respecto de la dificultad de rentar o comprar películas colombianas en el mercado legal y la facilidad de conseguir copias piratas.

De manera particular, las familias 1, 2, 3 y 4 de los estratos bajo y medio-bajo, señalaron que ir a cine no constituye una opción de recreación debido al alto costo del boleto y la falta de tiempo. "Nosotros trabajamos para vivir, no para pasar el tiempo", afirmó un miembro de la familia 1. La generación de mayor edad considera que los temas

8 Para un análisis de los cuellos de botella en la distribución y exhibición en México, véase Sánchez Ruiz (1998, pp. 61-75), y en Latinoamérica, Getino (1998). 
recurrentes de violencia y sufrimiento desde hace 20 años no son atractivos ya que es lo mismo que ven en televisión.

Por su parte, familias en los estratos medio y alto tuvieron opiniones divididas respecto de las películas nacionales las cuales conocen porque las han visto en la televisión o porque asisten ocasionalmente a los teatros a verlas. La generación adulta expresó su preferencia por producciones mexicanas o hollywoodenses mientras los jóvenes afirmaron que están abiertos a ver las películas colombianas o de cualquier nacionalidad con el objetivo de entretenerse y si las campañas de promoción son llamativas. "Recuerdo los comerciales de 'Rosario Tijeras' y de 'El Colombian dream'; estaban en todas partes y mis amigos y yo decidimos verlas", dijo un encuestado de la familia 5. También se observó que los jóvenes de clase media y media alta ven mucho cine en Internet, pero "descargar películas colombianas no es muy común. No tienen mucha fanaticada", dijo un miembro de la familia 7. Otra persona mencionó el apoyo a la industria nacional como el principal motivo para ver los largometrajes locales, pero no encuentra compañía para asistir. Finalmente, los estratos altos (familias 8, 9 y 10) piensan que los temas son muy locales y que deterioran la imagen internacional del país, pero pueden verlos si las críticas son favorables.

Esta heterogeneidad de opiniones entre las familias en los diferentes estratos y dentro de los estratos mismos da cuenta de las dificultades que cualquier producción nacional enfrenta en un mercado incierto donde poco se aprecia la representación propia en los contenidos audiovisuales. Sin embargo, si se consideran estas percepciones y se observa el comportamiento de la taquilla, se puede concluir que sí existe interés por estas películas. De hecho, se ha pasado de un lánguido $0.56 \%$ de asistencia anual a estrenos nacionales en 1997 a 13.88\% en 2006 con un declive posterior de $10.42 \%$ en 2008 y 10.29\% en 2009 (Proimágenes en Movimiento, 2009a).

\section{CONCLUSIONES}

La interpretación de la prioridad del fomento de la diversidad cultural en la realidad va más allá de la discusión simplista de la oposición entre el discurso oficial defensor de la diversidad cultural contra los intereses 
comerciales de los demás agentes porque, como se ha visto, incluso dentro de estos mismos hay contradicciones. De parte del Estado, por ejemplo, hay disparidad entre un discurso que aboga por la reducción de su tamaño a través de la descentralización y la re-regulación y concentración de poder existentes. Además, el contraste entre la financiación sostenible y la mayor proyección en el mercado de las iniciativas de tipo comercial del FDC frente a la dependencia estatal y circulación cerrada de aquellas apoyadas por el PAN dejan en claro que el espacio audiovisual tiene un largo camino que recorrer para ser considerado una herramienta y reflejo de la inclusión defendida por el modelo oficial.

El despegue de la industria cinematográfica y la lucha por la diversidad cultural representan las dos dimensiones del cine como industria cultural. Por eso la función social que los largometrajes de ficción pudieran llegar a cumplir necesita mucho más que buenas intenciones por parte del Estado y otros sectores aislados, ya que últimamente el éxito de estas políticas también depende de lo que funcione para las lógicas comerciales de los demás actores y el tipo de mercado donde son implementadas. Como se ha observado, los realizadores necesitan asegurar la financiación y lograr exhibir sus películas independientemente de si las narrativas o estéticas apuntan a un modelo comercial o cultural mientras distribuidores y exhibidores siguen ejerciendo amplio control sobre el mercado y las audiencias manifiestan sentimientos encontrados con respecto de la producción nacional.

En la actualidad, la marginalidad es el común denominador no sólo en cuanto a los sectores que participan en la construcción audiovisual sino también en la representación de los contenidos y el acceso, por eso se hace urgente generar consenso sobre la importancia de la inclusión de comunidades olvidadas en la representación identitaria que el cine ofrece. Los pocos puntos de encuentro de los intereses de los distintos agentes como el Cine Gira y el Ciclo Rosa demuestran que es posible ampliar los límites de la pantalla y canalizar las demandas de representación y acceso. Este desafío cobra mayor fuerza si se tiene en cuenta el contexto global donde los gobiernos latinoamericanos buscan firmar tratados de libre comercio en una posición de bajo poder de negociación respecto de las potencias económicas, poniendo en riesgo la reproducción del capital cultural a través de sus industrias culturales. 


\section{Bibliografía}

Álvarez, L.A. (2001). Cine en la última década del siglo XX: imágenes colombianas. Recuperado el 7 de agosto de 2009 de http://www. lablaa.org/node/20173

Congreso de Colombia (1997, 7 de agosto). Ley 397. Por la cual se desarrollan los artículos 70, 71, 72 y demás artículos concordantes de la Constitución Política y se dictan normas sobre el patrimonio cultural, fenómenos y estímulos a la cultura, se crea el Ministerio de la Cultura y se trasladan algunas dependencias. Recuperado el 1 de marzo de 2010 de http://www1.minicultura.gov.co/nuevo/cerodos/ DOCUMENTOS/Ley397.pdf

Congreso de Colombia (2003, 2 de julio). Artículo 1o. Ley 814. Por la cual se dictan normas para el fomento de la actividad cinematográfica en Colombia. Recuperado el 8 de enero de 2006 de http://www. cinelatinoamericano.org/assets/docs/ley\%20814.pdf

Convenio Andrés Bello (2003). El impacto económico de las industrias culturales en Colombia. Bogotá: Ministerio de Cultura: Convenio Andrés Bello.

Comisión Nacional de Televisión-CNTV (2008). Acuerdo No. 005. Bogotá: CNTV.

Cwi, D. (1982). Merit Good and market failure: Justifying and analyzing public support for the arts. En K. V. Mulcahy C. R. Swaim (Eds.), Public policy and the arts (pp. 59-89). Boulder, Colorado: Westview Press.

El público nacional está de romance con nuestro cine (2007). Kinetoscopio, 79, 58-60.

Eskpe (2005). El 2005 fue un año récord en taquilla para el cine colombiano. Recuperado el 10 de octubre de 2008 de http://eskpe.eltiempo.terra.com.co/secc_eskpe/2731864.html

Getino, O. (1998). Cine y televisión en América Latina: producción y mercados. Buenos Aires: Ediciones CICCUS.

Grant, P. S. \& Wood, C. (2004). Blockbusters and trade wars: popular culture in a globalized world. Vancouver, Canada: Douglas \& McIntyre.

Hall, S. (1997). The centrality of culture. En K. Thompson (Ed.), Media and cultural regulation (pp. 207-238). Londres: SAGE. 
Hesmondhalgh, D. (2007). The cultural industries. Londres: SAGE.

Historia de un fracaso (1993, 1 de marzo). Semana, 561. Recuperado el 27 de noviembre de 2006 de http://www.semana.com/wf_InfoArticulo.aspx? IdArt=53425

Hoskins, C.; McFadyen, S. \& Finn, A. (1997). Global television and film: An introduction to the economics of the business. Nueva York: Oxford University Press.

López, O. (2004). Las fuerzas económicas del mercado mundial del cine. Bogotá: Convenio Andrés Bello.

Los viajes del viento hace parte de la selección oficial de Cannes (2009, 23 de abril). El Espectador.com. Recuperado el 16 de septiembre de 2009 de www.elespectador.com/entretenimiento/agenda/cine/ articulo137373-los-viajes-del-viento-hace-parte-de-seleccion-oficial-del

Martínez Pardo, H. (1978). Historia del cine colombiano. Bogotá: Editorial América Latina.

Ministerio de Cultura (2010, 28 de mayo). Informe de gestión 20072010. Recuperado el 3 de marzo de 2010 de http://www.mincultura. gov.co/index.php?idcategoria $=37354$

Palacios Obregón, C. (2004). Pájaros y Escopetas. Altus En Línea. Bogotá: Universidad Sergio Arboleda. Recuperado el 6 de septiembre de 2009 de http://www.usergioarboleda.edu.co/altus/critica_cine.htm

Patiño, F. (2006, noviembre). ¿Cómo y dónde exhibir los trabajos audiovisuales? Ponencia presentada en el Primer Encuentro Distrital Audiovisual. Bogotá.

Picard, R. G. (1989). Media economics: concepts and issues. Newbury Park, CA: Sage Publications.

Proimágenes en Movimiento (2009a). Espectadores y taquilla del cine colombiano 1996/2009. Recuperado el 28 de diciembre de 2009 de http://www.proimagenescolombia.com/archivos/520_taquilla_espectadores_cinecol_sep2009.xls

Proimágenes en Movimiento (2009b). Recaudos para el Fondo de Desarrollo Cinematográfico (hasta febrero 2009). Recuperado el 28 de diciembre de 2009 de http://www.proimagenescolombia.com/ archivos/383_recaudofdc_feb2009.xls 
Proimágenes en Movimiento (2009c). Salas de cine 2009 (por exhibidor, ciudad, departamento). Recuperado el 28 de diciembre de 2009 de http://www.proimagenescolombia.com/archivos/525_salasdecine_2009.xls

Sánchez Ruiz, E. (1998). Cine y globalización en México: el desplome de una industria cultural. Comunicación y Sociedad, 33, 47-91.

Suárez, J. (2007). La estrategia del futuro: ¿hemos de tener cine global? Kinetoscopio, 79, 79-86.

Taquilla en rojo. (1983, 16 de mayo). Semana, 50. Recuperado el 27 de noviembre de 2006 de http://www.semana.com/wf_InfoArticulo. aspx?IdArt $=61060$

Thompson, K. (Ed.). (1997). Media and cultural regulation. Londres: SAGE.

Organización de las Naciones Unidas para la Educación la Ciencia y la Cultura-UNESCO (2005). Convención para la Protección y Promoción de la Diversidad de Expresiones Culturales. París: UNESCO.

Uno no va a cine a que le echen un discurso político (2007). Kinetoscopio, 79, 28-31. 